Creating new career pathways to reduce poverty, illiteracy and health risks, while transforming and empowering Cambodian women's lives'.

Helen Lee, Psychology, Staffordshire University, UK

Gabe Pollock, Psychology, University of Guelph, Canada

lan Lubek Psychology, University of Guelph, Canada ; and National Centre in HIV Social

Research, University of New South Wales, Australia

Sarath Kros, Head, Siem Reap Provincial AIDS Office; Assistant Director Provincial Health

Department; Director (PT), SiRCHESI, NGO, Cambodia

Neela Griffiths, ELSSA Centre, University of Technology, Sydney; Australian Volunteers

International, and SiRCHESI (NGO)

Brett Dickson, Australian Volunteers International; SiRCHESI, NGO

Noeun Pring, SiRCHESI, NGO; Cambodia

Kris Sohkurt Huon-Ribeil, SiRCHESI NGO, Cambodia

Natalie Lim, Flinders University, Adelaide, Australia

Jasmin Turner, Flinders University, Adelaide, Australia

Vanna Ma, SiRCHESI NGO; Provincial AIDS Office, Cambodia

Sophiap Prem, SiRCHESI NGO, Cambodia

Virakboth Huot, Provincial AIDS Office, Cambodia

Stacy Niemi, Psychology, University of Guelph, Canada

Chris Winkler, Psychology, Macquarie University, Australia

Katie O'Brien, Psychology, University of Guelph, Canada

Sabina Bashir, Psychology, University of Guelph, Canada

Ellyn Braun, Psychology, University of Guelph, Canada

Mee Lian Wong, School of Epidemiology and Public Health, National University of Singapore

Tiny van Merode, School of General Practice, University of Maastricht, Netherlands

Roel Idema, Maastricht, Netherlands

Bun Chemm Dy, Director, Siem Reap Provincial Health Department, Cambodia 


\title{
Creating new career pathways to reduce poverty, illiteracy and health risks, while transforming and empowering women's lives.
}

\begin{abstract}
Community health psychology has provided a framework for members of a community to bring about change in health and social inequalities. As part of an ongoing SiRCHESI participatory action research (PAR) project, a 24 month Hotel Apprenticeship Program was introduced in 2006 to provide literacy, social skills and health education, hotel training and work experience, plus a living wage for young, female beer sellers facing workplace risks including, HIV/AIDS, workplace harassment, alcohol overuse and violence. This paper reports quantitative and qualitative analyses of changes in health-related knowledge, behaviour and empowerment of HAP trainees and tentatively suggests positive changes have occurred.
\end{abstract}

\section{PAR as a model for community health interventions in Cambodia}

From early work on action research by Lewin $(1946 ; 1947)$ and its development by Chataway (1997), in drawing influence from Martín-Baró's (1994) liberation psychology and Freire's (1970) notion of conscientization, PAR has evolved as important in critical community health psychology (Brinton Lykes, 2000; Brydon-Miller, 2004; Curtis, Bryce \& Treloar, 1999; Murray \& Campbell, 2003). Equal participation of community members is held integral and their empowerment viewed central as they work with researcher/activists to identify problems and instigate actions towards resolution and social change (Campbell \& Murray, 2003; Jacobs, 2006; Murray \& Poland, 2006). While theory, research and practice are all intertwined, primary attention centres on research and evidence-guided interventions to address immanent and threatening health crises.

The NGO SiRCHESI (Siem Reap Citizens for Health, Educational and Social Issues) begun in 2000, introduced a model of PAR to focus on women beer sellers. Lubek et (2002) and Lubek \& Wong (2003) depict SiRCHESl's early work in addressing the HIV/AIDS and other workplace risks of beer sellers. The challenges and dangers these women face nightly in terms of alcohol overuse at work and sexual and physical abuse perpetrated by customers have been described in industry-financed studies (Quinn, 2003, Bury, 2005, Klinker, 2005, CAS, 2009) as well as in research done in conjunction with SiRCHESI (McCourt, 2002; Schuster, 2006; Pagnutti, 2006; Lubek, 2005; Lubek 2009; Lubek et al, 2009). The latter studies also documented their poor remuneration (\$50-65 per month between 2002-2008) on average less than half what they need to feed their 
families and how some become "indirect sex workers" (NCHADS, 2003) to make financial ends.

This paper reports on a Hotel Apprenticeship Program (HAP) which forms part of a wider SiRCHESI PAR project centred in Siem Reap, Cambodia. It assesses the effectiveness of the HAP which is to empower former beer sellers through the process of education and training, raising consciousness and awareness about former workplace risks and exploitation while providing literacy, skills training and the experience of safer, upwardly mobile careers within the hotel industry.

\section{SiRCHESl's Hotel Apprenticeship Program (HAP)}

The HAP introduced in 2006, aimed to remove beer sellers from their hazardous workplaces and place them into healthier, safer and more financially secure jobs. It developed from discussions with beer sellers where they talked of a preference for hotel work: some indicated they had first applied for hotel jobs, and were rejected, before then becoming beer sellers (Pollock, 2008). Reasons given for rejection included lack of necessary job skills, Khmer literacy and conversational English. The HAP was designed to deal with both management's hiring criteria and the anecdotal rejection stories from beer sellers. Thus, the program's interventions were designed to meet simultaneously the needs of all stakeholders.

By early 2006, there was already local interest from hotel managers, and from beer sellers wishing to change careers, but foundation funding was needed that would last at least 2 years before any commitments could be made for the first cohort of students. Other existing hotel industry educational programs were observed and consultations held. Short questionnaires were collected from local hotel managers and their answers then fed back at later meetings; this PAR activity helped us jointly plan the program of partnership for SiRCHESI's HAP. Two Cohorts were funded, with about $60 \%$ (until January, 2009) coming from SiRCHESI's M.A.C. AIDS Foundation partner, and 40\% from the partner hotels - Lin Ratanak, Sokha and Angkor Howard (with the Raffles Grand Angkor cancelling the day before selection interviews were to begin). This partnership balance was calculated to change, as women were promoted up the hotel's regular salary ladder. It was then planned to present a fully evaluated and costed program blueprint to the Cambodian Hotel Association to show how they could continue such a program at $100 \%$ funding, without NGO participation, in order to increase the presence of women in the industry for a rather small, per capita training cost. 
Women were recruited by SiRCHESI through workplace and workshop interviews assessing current health and safety risks; then joint interviews were held with hotel managers who selected candidates to work in their hotels. Cohort 1, launched in 2006, started with fourteen trainees (November 2006 - November 2008) and Cohort 2 was launched with sixteen trainees (September 2007 - September 2009). With lessons learned from Cohort One, SiRCHESl's pre-screening of eligible candidates for Cohort 2 now included home visits by the teaching staff, to ensure that such a career shift for at least 2 years had the support and agreement of the relevant support network (e.g., spouse, parents/babysitters for children). Then final interviews were conducted with 6 hotel managers to fill the 16 available training positions, and an additional 2 hotels taking trainee transfers during 2008.

The program was jointly designed with hotel partners to train beer sellers to work conscientiously in these local hotels, while at the same time developing Khmer and English literacy as well as improving their health-related knowledge and behaviour, and their life and social skills. Also it was hoped that having a steady job and the transformation to a "living wage" would end all risk-taking, reduce alcohol consumption, and produce a transformation in self-image and self-competence.

Pollock (2008) describes the program as it began with an eight-month apprenticeship stage, during which trainees participated in morning classes at the SiRCHESI school as well as undertaking an internship in a three or five-star hotel, with 9-hour shifts beginning after lunch. The guaranteed monthly 'living' wage of $\$ 110$ was set, following surveys from 2002-2006. The school portion of the day included: i) classes in English and Khmer, with emphasis on vocabulary useful to the hotel industry; ii) health-related education, including reproductive and sexual health knowledge (e.g. HIV/AIDS, condom use, family birth spacing) and knowledge about the dangers of alcohol; and iii) life and social skills education. The SiRCHESI school also had a counsellor available to the trainees.

Thus this HAP created a community partnership between a Foundation, an NGO, international researchers and students, local hotel industry management, with additional cooperation coming from government agencies such as the Provincial AIDS Office, Provincial Health Department, and Department of Women's Affairs. But also, with its specific focus on reducing HIV/AIDS, literacy and education, improving workplace health and safety, economic security and welfare, and empowerment of women, it managed to address important aspects of the UN Millennium Development Goals. 
The quantitative analyses below, principally looking at Cohort 1 students, draw heavily from Pollock (2008). The HAP was designed with various assessments of progress, including self-reports of knowledge, behaviour, motivation, and job satisfaction, as well as repeated measures by SiRCHESI staff and Hotel supervisors, concerning trainees' academic progress and job performance. For Cohort One trainees, data were gathered on all 14 (female) trainees, they were followed for 8 months (in school and working at their hotels), and then for the next 16 months (full-time in the hotel). Attempts were made to keep up with all students, even if some left the program before the 24 months were over. Thirteen had been employed as beer sellers prior to the program, while one had been working in the kitchen in a beer restaurant. At the beginning of the program participants: were between 19 and 31 years old $(M=24.93, S D=3.77)$; had an average of 5 years of formal education $(S D=2.08)$, with a range of 2 to 8 years; had between 1 and 8 dependents $(M=4.36, S D=2.37)$ and between 0 and 4 other people contributing to household income $(M=1.21, S D=0.98)$; also five participants had one child, and one participant had two children. These data are similar for the beer-seller demographic profiles seen in previous SiRCHESI studies (McCourt, 2002; Schuster, 2006; Pagnutti, 2006).

The quantitative evaluation of all candidates began half-way through the program for cohort 1 , and no pre-program baseline measure had been taken at start-up. To measure change during the program, it was decided to use the data from a matched sample of fourteen beer sellers, extracted from SiRCHESl's cumulative database of beer-seller health workshop interviews (2005-2007). It was at these workshops, that many of the HAP trainees were recruited. Because of confidentiality, the actual names of persons who attended were not recorded. Three of the 14 students in fact later confirmed during interviews that they had in fact participated in these workshops. Pollock (2008) therefore created a "matched sample" of 14 workshop beer-sellers with our 14 HAP student trainees ${ }^{2}$.

$A$ self-report Hotel Apprenticeship questionnaire was administered to the trainees at various points during training. This questionnaire was adapted from previous SiRCHESI health workshop instruments used between 2002 - 2008, with additional questions added as needed for specific projects (for example, see Schuster (2006) who compared Cambodian and Canadian samples and Pagnutti (2006) who compared men drinkers and women beer sellers). Parallel questions were added concerning workplace health and safety in the hotel situation. In this paper, findings about health-related knowledge and behaviour are reported. This includes i) a composite indicator of the five key questions 
pertaining to knowledge about HIV/AIDS prevention (recommended by the United Nations General Assembly Special Session on HIV/AIDS (UNAIDS) (2007); ii) questions about condom use; iii) reports of nightly and weekly alcohol consumption; iv) reports about job satisfaction; and v) measures relating to self-esteem. Trainees, with the help of SiRCHESI staff, completed this questionnaire at various points during their training; halfway through the school and apprenticeship stage (5 months into the program), at the end of the school stage (8 months), almost half-way through the program (14 months), and close to the end of the program (21 months). Follow-up interviews were later done at 27 months, when the program had finished.

A 14-item School Performance Appraisal was used to assess performance and learning in English, health and social skills learning, and general classroom performance. It included 10 academic qualities (e.g. 'Dictation results'), each rated on a 4-point scale from 1 (Fair/below standard) to 4 (Outstanding/excellent), and four questions for additional comment by the English teacher and the program counsellor. These assessments were complete on a weekly basis between January and March 2007 and on a biweekly basis during April to July 2007. Due to the challenges of school start-up, no assessments were completed in December 2006, the first month of the program. Development of the School Performance Appraisal questionnaires followed a review of the academic assessment literature and consultation with the program teachers.

\section{Quantitative findings about HIV/AIDS, Health Knowledge and Behaviour ${ }^{3}$}

For the composite measure of HIV/AIDS knowledge, complete longitudinal data until month 21 was available for 6 students. A one-way repeated measures ANOVA showed a significant improvement in HIV/AIDS knowledge, $F(3,15)=7.50, p=.003$, between the matched baseline group $(M=3.83, S D=0.75)$ and the students measured at 4-months $(M$ $=4.83, S D=0.41)$, 8-months $(M=4.83, S D=0.41)$, and 21-months $(M=4.83, S D=0.41)$ (the question was not asked in the 14-month assessment). All Cohort 1 participants, whether they stayed 21 months $(\mathrm{N}=7)$ or dropped out sooner $(\mathrm{N}=7)$, possessed an equally good knowledge about preventing HIV/AIDS (a one-way independent measures ANOVA $F(1,12)=0.00, p=1.000$, such that dropouts $(M=4.79, S D=0.39)$ and non-dropouts $(M$ $=4.79, S D=0.39)$ had identical scores.

\section{Condom Suggestion, Condom Use and Condom Negotiation}

Matched beer-servers and Cohort 1 trainees were compared to see how women were requesting use of a condom during their last sexual encounter with a partner. There was 
no significant change in condom suggestion, $\mathrm{X}^{2}(1)=0.24, p=.622$, between baseline $(n=$ 12 where $66.7 \%$ suggested) and in-program responses, $73.9 \%$. (For the latter, there was a total of $n=23$ responses across 3 in-program evaluations, with $N=11, N=6$, and $N=6$ respondents respectively.) There was no significant difference in condom suggestion, $X^{2}(1)=1.17, p=.278$, between dropouts (87.5\% suggestion) and participants $(66.7 \%)$.

Turning to the actual measure of condom use during the last sexual encounter with a partner, comparison between baseline with all intervention responses during the program showed no significant change in condom use, $x^{2}(1)=0.60, p=.439$, between baseline ( $n=11$, condom use 63.6\%) and in-program ( $n=29$ responses, condom use $75.9 \%$ ) - these figures closely map condom suggestion, above. There was a difference in condom use during the last sexual encounter (measured across all in-program assessments) between program dropouts $(n=7)$ and participants who remained with the program ( $n=15$ responses), $x^{2}(1)=3.85, p=.050$, such that dropouts $(100.0 \%$ use) had higher condom use rate than participants $(60.0 \%$ use). Chi square tests showed no differences in success rate in condom negotiation among participants who suggested using a condom, whether baseline vs trainees, drop-outs vs participants who remained, rates varied between $80-100 \%$.

\section{Nightly and Weekly Alcohol Consumption}

When comparing the reported number of litres of alcohol drunk in a single night, a one-way repeated measures ANOVA was carried out among the six participants for whom complete longitudinal data for this scale was available. There was a statistically marginal change in beer consumption, $F(1,6)=5.32, p=.051$, between baseline $(M=1.23$ litres nightly, $S D=$ 1.06), 4-month ( $M=0.29, S D=0.46)$, 8-month $(M=0.00, S D=0.00)$, 14-month $(M=0.04$, $S D=0.10)$, and 21 -month $(M=0.18, S D=0.14$, $)$ The practice of heavy drinking of 5 standard drinks was greatly reduced to near 0 in the 8 and 14 month evaluations. In addition, when looking at the larger sample of 14 HAP participants and their matched baseline group, a one-way repeated measures ANOVA for consumption between baseline and intervention stages $(n=14)$, found a significant decrease in alcohol consumption, $F(1$, $13)=7.49, p=.017$, from baseline $(M=0.82, S D=0.80)$ to intervention stage $(M=0.17$, $S D=0.29$ ) (this translates into a very practical reduction from more than 3 standard drinks nightly to under 1 standard drink). What is interesting to note about the program is that even when participants dropped out, they drank alcohol quite modestly. Thus there was no significant difference in nightly alcohol consumption, $F(1,12)=0.99, p=.339$, between 
dropouts $(M=0.10, S D=0.11)$ and non-dropouts $(M=0.25, S D=0.39)$, with both consuming 1 or less standard drinks at the last drinking event.

Alcohol use was also measured as frequency of nights of consumption per week. There was a significant decrease in weekly alcohol consumption, $F(1,13)=72.90, p<$ .001 , from baseline $(M=5.25, S D=2.28)$ to intervention stage $(M=0.05, S D=0.12)$. And the effects of reduced drinking remained even if one left the program: there was no significant difference in weekly alcohol consumption in nights of drinking, $F(1,12)=0.15, p$ $=.167$ between dropouts $(M=0.10, S D=0.16)$ and non-dropouts $(M=0.00, S D=0.00)$.

\section{Academic Progress: English Proficiency and the Health and Social Skills Learning Scale} Degree of learning English was assessed for twelve participants for whom complete longitudinal data for this scale was available. There was a significant change in English learning over time $F(2,31)=6.37, p=.002$. English proficiency scores were nearly identical for those who stayed in the program $(\mathrm{N}=7, M=12.43, S D=1.48)$ and those who left $(\mathrm{N}=7 M=12.23, S D=2.89)$, with no significant difference $F(1,12)=0.03, p=.872$.

A significant change in health and social skills learning was seen with $F(6,54)=2.62$, $p=.027$ among the 7 measured months, starting at January $(M=6.00, S D=0.94$ and ending July $(M=6.40, S D=1.58)$. There was no significant difference in health and social skills learning scores, $F(1,12)=1.40, p=.260$, between dropouts $(M=5.95, S D=1.10)$ and non-dropouts $(M=6.50, S D=0.55)$.

\section{Qualitative data}

The qualitative data draws from a body of video-recorded semi-structured interviews with cohort 1 and 2 students, cohort 2 student presentations at the SiRCHESI school and researcher and teacher observations. Nine cohort 1 students were interviewed at 21 months into the program. Of these, seven were still active in the program and two had left but returned to give feedback. Sixteen cohort 2 students were interviewed at 12 months and 22 months into their program. Simultaneously, questions and responses were translated and transcribed. The transcripts were later verified against the video recordings and anonymized. Questions centred on i) experience working as a beer seller and in the hotel, ii) what if anything they would like to tell or teach a current beer seller, and iii) whether they had future plans.

The transcripts were read many times and coded into emerging themes - coercion, safety, education, skills, choice, being looked down on, respect and hope. Along with 
cohort two SiRCHESI school presentations and research and teacher observations, the interview transcripts triangulate and add additional insights to the quantitative measures.

\section{Qualitative analysis}

The quantitative measures suggest that compared to baseline beer sellers, the trainees displayed a significant increase in health-related knowledge and behaviour in two of three risk areas - increase in knowledge about HIV/AIDS prevention and alcohol consumption. There was a dramatic decrease in alcohol consumption - measured by litres of alcohol consumed per night and nights of alcohol consumption per week; leaving the job of beerserver thus greatly reduced the health risk from alcohol overuse, both for trainees that stayed for almost 2 years with our program and for those who dropped out before the end of the program. This is substantiated by the qualitative interviews in which apprentices were asked about beer selling and how it compares to working at the hotel ${ }^{4}$.

One thing that's completely different in the hotel restaurant is that no one forces her to drink. No customers are ever inappropriate in the restaurant, the restaurant has its own rules (interview 18)

It was a very bad job, sometimes the clients would look down on her. It was a risky job, sometimes the customers would force her to drink or ask her to sleep with them (interview 16)

When asked what they would teach beer sellers, replies included 'don't drink too much beer, beer will be harmful to your health' (int 26). Other trainees gave more detail about how alcohol impacts on health and carries the additional risk of being drugged.

Her skin looks better now than before, because she's not drinking, because she's healthy, before I had stomach ache, because I drink beer a lot (Interview 36)

She would tell them [current beer sellers] to find a way not to drink. If they go with the tourists, they have to try to prevent bad things from happening and if they smell the beer and it smells funny, to be very careful because sometimes customers drug the beer (interview 13)

No overall change was documented in quantitative measures of condom use. This was assessed through i) reported condom use during last sexual encounter, ii) suggesting using a condom during last sexual encounter, and iii) condom negotiation success rate. There were no significant overall changes in these indicators throughout the program, and all three condom-related indicators showed the lowest rates at the final 21-month assessment. It should be pointed out that the beer sellers were sometimes having sex 
both with partners and with paying clients, while students in the program did not have paying customers. Indeed, the qualitative interviews demonstrated the trainees did have knowledge about the importance of condom use pertaining to beer sellers. Among answers to the question 'if you were asked to teach a beer seller, what would you teach them?' responses included,

She tell them how to use the condom all the time, if can use the condom all the time, it [HIV] cannot pass (interview 28)

Tell them, don't drink too much, can lose control, use their emotions and sometimes they can forget to wear their condoms (interview 36)

The quantitative measures suggest that health and social skills learning and English proficiency changed significantly throughout the program. While there was no significant difference between in English proficiency scores between those who stayed in and those who left the program, it seems giving English skills in the Siem Reap tourism context may be equally helpful for those staying in their hotel jobs, and for those moving to other jobs. The qualitative interviews offer understanding of the importance of learning English and other skills for these former beer sellers as they are evidence that education and training offer an opportunity to leave behind a workplace replete with dangers, to take on not only a new job, but also a healthier lifestyle. Illiteracy, a lack of education and skills are talked about as restricting opportunity and placing the young women in a position where they have no choice but to become a beer seller; and consequently are coerced into undesirable, potentially harmful behaviours.

She didn't like being a beer girl but she had no choice. She had a very low education, no English and she had no connections to get a job (interview 16)

However, since entering the SiRCHESI program - as a hotel trainee and student in the school program - ex-beer sellers talk of having opportunities of choice and, in consequence, a sense of hope for the future. Indeed there is a marked shift in interview 16 between depicting being a beer seller without any choice (extract above) and the hope she has for the future because of the skills 'abilities' she has acquired (see below).

She is hopeful for the future. Because of her current job today and her abilities now she feels hopeful (interview 16) 
Many of the other apprentices talked of hope and aspirations because of the skills they have learnt through SiRCHESl's apprenticeship program.

\begin{abstract}
She has gained skills from the program that will help her get other jobs. She hopes she can use all of the skills from the program for the future. This program gives her hope (interview 2)

I am very happy at SiRCHESI school, because I have an excellent teacher. I have good friend. I have a good salary. I have a safe job and I then I change my behaviour and stopped I have stopped drinking beer in September. In the future, I want to be a receptionist. When I can speak English very well I want to work in NGO (SiRCHESI school, presentation 1)
\end{abstract}

However, differences did occur among the apprentices in terms of the extent to which they were able to develop their command of English. Researcher and teacher observations add insight in explaining that lack of English at the beginning of the program meant apprentices were often placed in departments where English would not be as important as there was no contact with international guests e.g., cleaning and laundry. After the eight-month apprenticeship stage of the program ended, and with it the daily English education, participants in areas where they could not practice English began to lose the language; further hampering their chances of changing to a better job within the hotel. Remedial English classes, offered by SiRCHESI as a late addition to the program, had low and sporadic attendance, because of participants' changeable and generally very busy work schedules.

The Cohort 1 English teacher wrote recommendations in School Evaluations that one-on-one tutoring was needed in order to improve the English level of some students especially students with little prior formal education. Difficulties are highlighted by one participant who talked of eight-hour shifts in addition to family and other concerns external to the program which did not allow for the possibility of coming to the SiRCHESI school for more training. Other participants were chastised at work for reading (presumably studying) during their shifts, though were praised for studiousness in SiRCHESI school evaluations.

When the program was set up, one aim was for trainees to be transferred between different departments to learn various skills. So, less attention was paid to the department where they began training. Certain jobs were sought after because they provided useful skills that could be transferable, within and outside the hotel - cook, cashier, spa worker. Working as a "public area" cleaner was viewed as unchallenging. Other participants noted the transferability of skills learned as cook or cashier to potential future employment including working in the central market and cooking. Moreover, some trainees were aware 
that some hotel jobs (e.g. housekeeping, waiter, and spa jobs) included the possibility of tips, which could supplement their income and help them attain a 'living wage' when the SiRCHESI fellowships ended after 24 months. Nevertheless, some department heads and managers were reluctant to move participants once they had received training in one department, with decisions based largely on department needs, rather than employee motivation or preferences.

An additional challenge affecting the future of these apprentices and the attainability of a 'living wage' from hotel work is the economic downturn in 2009. Fewer tourists were visiting Cambodia and staying in the hotels; this has meant that some of the apprentices have had work hours and wages reduced ${ }^{5}$.

She still happy to work in the hotel, even now with the bad economy. But the hotel still give her half work, work 15 day, and half pay, because of the economy, everyone in the hotel (interview 31)

However, none of the apprentices interviewed mentioned resorting back to beer selling or indirect sex work.

\section{Discussion}

Although based on a relatively small sample the analysis goes some way to suggest that the HAP is effective in increasing health-related knowledge regarding alcohol use, HIV/AIDS and condom use, and reducing risky behaviour with regards to alcohol consumption. However, while knowledge about condoms and HIV/AIDS was demonstrated in the qualitative data, the quantitative measures did not show a significant difference in condom suggestion. Schuster (2006) and Wong et al (2003) argue that Cambodian relationships based on love and/or trust, have the lowest rates of condom use. One effect of steady well-paid, safe and healthy employment was an increased number of married trainees who were not using condoms because they were trying to become pregnant. They trusted that their husbands were monogamous and not spreading HIV/AIDS and sexuallytransmitted infections; this may partially account for the inconsistent use of condoms late in the program. However, Schuster (2006) argues many Cambodian men are not monogamous; approximately 20-25\% local men reported having paid sex during the preceding year (often without condoms). This has created a 'bridging pattern' of infection, to wives and future children, from sex workers via their husbands. Given the major transmission pattern through husbands and boyfriends, additional emphasis on this in the program is needed. 
Through an education and skills-based training program analysis suggests this project has raised awareness about HIV/AIDS, condom use and the risks of alcohol. The removal of these young women from the context of beer selling - and associated workplace risks - to hotel work means not only have they gained knowledge but also, they have the opportunity to engage in healthier behaviours. Economic security has meant they do not have to supplement income with indirect sex work. Moreover, some literacy in Khmer and English as well as skills training in the hotel industry seems to have empowered the women towards future careers, economic mobility and a more valued position within a wider context of people living Siem Reap. This change is summed up by one trainee, who prior to graduation commented to her teacher:

In the beer garden is no good job. I have many problems when I drink a lot of beer and I have no empowerment. Look down on me from the guests. Not safe, not secure and no respect. In the hotel is a good job. In the hotel I have good knowledge and good skill and stable income, supported by society. In the future I want to work for an NGO and help the women in Cambodia.

\section{On reflection: participatory issues and future concerns}

As the HAP largely involved a top-down delivery of education and skills training ${ }^{6}$, it resembles what Jacobs' (2006) depicts as lower level participation. However, Jacobs argues levels of participation shift throughout a PAR project - often with higher levels during assessment and planning, and lower levels at intervention and evaluation. This is the case with SiRCHESI's PAR project. While the research presented here is based on interviews by researchers including the project director and international advisors, as well as psychometric assessments, all useful for future funding applications but with a relative imbalance of power, the extent to which the women's 'voices' can be heard is limited. On reflection, future evaluations could consider the use of participatory methods inspired for instance by Brinton Lykes' (2004) work with photovoice, with the aim of giving more control and 'voice' to the women and accessing a more detailed narrative of changes taking place in their lives.

Jacobs (2006) is also critical of the notion that it is equal participation that leads to empowerment; she argues lower levels of participation (e.g., taking part in an initiative but not in its organisation) can also be empowering and lead to higher level participation. This is evident in the HAP, where despite engaging at a lower participatory level in delivering education and skills training, also has two trainees talking about wanting to work for an NGO, one of whom wants to 'help women in Cambodia'. 
The HAP is one aspect of a much wider PAR project which develops peer education, outreach and workshops with beer sellers as well as other women and men living in Siem Reap, and also as is encouraged in critical community health psychology (Murray \& Poland, 2006), works towards macro-level change in targeting the brewers whose beer is sold by beer sellers in Cambodia, in an attempt to address inequalities in relation to health, education and poverty (Lubek, 2005; Lubek et al, 2002; Lubek et al, 2009). The attention to poverty and illiteracy experienced by these former women beer sellers, together with a reduction in workplace risks, has been in the spirit of the UN Millennium Goals.

\section{NOTES}

1. The research reported here has been supported (2000-Jan., 2009) by various grants from Elton John AIDS Foundation, M.A.C. AIDS Fund, Rotary International, and individual and corporate donations. Portions of this manuscript are drawn directly from the University of Guelph Honours Thesis of Gabe Pollock (2008), under the direction of lan Lubek.

2. This matching was based on three categories: age, years of formal education, and beer brand/brewer. Matches were considered acceptable if the difference in education was within 1 year, age was within 3 years, and beer family was the same. For the one participant who had not worked as a beer seller, beer company was not considered as a matching criterion. When finding matches for the 14 women entering the program in November 2006, baseline data gathered in 2006 were given preference; where most of the HAP recruiting was conducted. Both groups had identical beer company affiliations, with three participants (and their matches) working for Heineken, one participant (and her match) working for AB INBEV/INBEV, one participant (and her match) working for Carlsberg, and nine participants (and their matches) working for "other" brands.

3. Additional analyses of the quantitative measures are found in Pollock (2008).

4. The transcripts record the voice in English of the interpreter, who often translates into the third person, e.g., "She says that..."

5. SiRCHESI has extended partial fellowships beyond Nov. 2008 for Cohort 1 students, and is also doing likewise for Cohort 2 beyond Aug. 2009, until the economic situation improves in their hotels.

6. Some lessons were less 'top-down' as they were adapted to accommodate the work situation e.g., a menu a trainee was given to learn became the focus of an English module, 'hygiene requirements for employees' became a role play session for the whole class.

\section{REFERENCES}

Brinton Lykes, M. (2000). Possible contributions of a Psychology of Liberation: Whither health and human rights? Journal of Health Psychology, 5(3), 383-397.

Brydon-Miller, M., (2004). Using participatory action research to address community health issues. Chp in M. Murray (Ed.). Critical Health Psychology. London: Sage. 
Bury, L. (2005). A report on the situation of beer promotion women in the workplace, Cambodia: results of a harassment and abuse survey. Phnom Penh: CARE Cambodia.

Campbell, C., and Murray, M. (2004). Community health psychology: Promoting analysis and action for social change. Journal of Health Psychology, 9(2), 187-195.

CAS (2009) Compliance to and Impact of the BSIC Code of Conduct: Monitoring Survey. Center for Advanced Study, Phnom Penh April 2009

Chataway, C. (1997). An examination of the constraints on mutual inquiry in a Participatory Action Research project. Journal of Social Issues 53(4), 747-765.

Freire, P. (1970). Pedagogy of the Oppressed. New York: Continuum.

Jacobs, G. (2006). Imagining the flowers, but working the rich and heavy clay: participation and empowerment in action research for health. Educational Action Research, 14(4), 569-581.

Klinker, C. (2005, February). Selling Beer Safely: A Cambodian Women's Health Initiative - Endline Evaluation. Phnom Penh: CARE Cambodia.

Lewin, K. (1946). Action research and minority problems. Journal of Social Issues, 2(4), 34-46.

Lewin, K. (1947). Frontiers in group Dynamics: II. Channels of Group Life; Social Planning and action research. Human Relations, 1, (2), 143-153.

Lubek, I. (2005). Cambodian 'beer promotion women' and corporate caution, recalcitrance or worse? The Psychology of Women Section Review 7(1), 2-11.

Lubek, I. (2009) AB-INBEV, Carlsberg, Heineken and other international brewers are yet again in 2008-9 behaving badly to women beer sellers in Cambodia. Available at:

http://www.ethicalbeer.com/read/April2009-INFO.pdf

Lubek, I., Lee, H.A., Wong, M. L., van Merode, T., Kros, S., McCourt, M., Schuster (Crocker), J., Pagnutti, T., Ganapathi, S., Cadesky, J., Pollock, G. \& Idema, R. (2009). The life of a beer seller in Cambodia-to die for? La vie d'une vendeuse de bière au Cambodge- à mourir? Cahiers du Genre, 45, 77.102.

Lubek, I., Wong, M. L., McCourt, M., Chew, K., Dy, B. C., Kros, S., Pen, S., Chhit, M., Touch, S., Lee, T. N., \& Mok, V. (2002) Collaboratively confronting the current Cambodian HIV/AIDS crisis in Siem Reap: a cross-disciplinary, cross-cultural "Participatory action research" project in consultative, community health change. Asian Psychologist, Vol 3, (1) 21-28.

Lubek, I., and Wong, M. L. (2003). Sites, camera, action: Contemplating the relations among theory, Lewinian "action research" and a community health intervention while touring the Angkor Wat temples. In N. Stephenson, H. L. Radtke, R. Jorna and H. Stam 
(Eds.), Theoretical Psychology: Critical contributions. Toronto: Captus Press.(Pp. 348357).

McCourt, M. (2002). A Social Psychological, Grassroots Empowerment Pilot Project for "Beer Girls" (Female Indirect Sex Workers) in Cambodia. Unpublished undergraduate thesis, University of Guelph, Guelph, Ontario, Canada.

Martín-Baró, I. (1994). Writings for a liberation psychology. In A. Aron \& S. Corne (Eds.), Cambridge, MA: Harvard University Press.

Murray, M., and Campbell, C. (2003). Living in a material world: Reflecting on some assumptions of health psychology. Journal of Health Psychology, 8(2), 231-236.

Murray, M., and Poland, B. (2006). Health psychology and social action. Journal of Health Psychology, 11(3), 379-384.

Pagnutti, T. (2006). Male Drinking and Subsequent Health Risks for Both Male Customers and Female Employees in Cambodian Beer-Selling Workplaces. Unpublished undergraduate thesis, University of Guelph, Guelph, Ontario, Canada.

Pollock, G. (2008) A Multi-method Assessment of SiRCHESl's Hotel Apprenticeship Program for Women Formerly Selling Beer in Cambodia. Unpublished undergraduate thesis, University of Guelph, Guelph, Ontario.

Quinn, I. (2003). Selling Beer Safely: A Baseline Survey and Needs Assessment of Beer Promoters in Phnom Penh. Report prepared for CARE International, Sept 2003.

Schuster, J. (2006). Women's Health Risks in Cambodian versus Canadian Beer-Selling Work-places. Unpublished Hons B.A. thesis, University of Guelph, Guelph, Ontario, Canada.

United Nations General Assembly Special Session on HIV/AIDS (2007). Monitoring the Declaration of Commitment on HIV/AIDS: Guidelines on Construction of Core Indicators. Geneva, Switzerland: UNAIDS.

Wong, M. L., Lubek, I., Dy, B.C., Pen, S., Kros, S., Chhit, M. (2003). Social and behavioural factors associated with condom use among direct sex workers in Siem Reap, Cambodia. Sexually transmitted infections, 79(2), 163-5. 